\title{
Wildlife Toxicology: Where We Have Been and Where We Are Going
}

\section{Ronald J Kendall*}

Wildlife Toxicology Laboratory, The Institute of Environmental and Human Health (TIEHH), Texas Tech University, Lubbock, Texas, USA

\begin{abstract}
Over the last three decades, the field of wildlife toxicology involving the assessment of toxic chemicals on the reproduction, health, and well-being of wildlife species has grown dramatically as a science involving both laboratory and field research. In the early years of the development of wildlife toxicology, there was a strong emphasis on laboratory toxicity tests, including $\mathrm{LD}_{50}$ and $\mathrm{LC}_{50}$ tests, particularly on species such as bobwhite quail (Colinus virginianus) and mallard ducks (Anas platyrhynchos). Laboratory tests evolved into largescale field efforts, particularly in the late 1980s and throughout the 1990s, which was facilitated by pesticide re-registration requirements to obtain data to submit to the United States Environmental Protection Agency. Now, as wildlife toxicology continues to evolve as a science, sublethal monitoring of wildlife has become much more prominent to assess health impacts. New developments in molecular biology have also allowed insight into the genetic basis for wildlife response to toxic substances. Considering the diversity of fish and wildlife species both in the United States and globally, it continues to be a great challenge to protect this diversity of wildlife species from impacts of toxic substances. As we expand and become more sophisticated in assessing field and laboratory effects of toxic substances in wildlife, we will be able to do a much better job in the future of assessing the effects of environmental contaminants on the reproduction and health of the wide array of wildlife species and developing solutions and/or mitigation strategies.
\end{abstract}

Keywords: Wildlife; Toxicology; Contaminants; Biodiversity; Toxicokinetics

\section{Introduction}

Over 30 years ago, Environmental Science and Technology published a feature article, "Wildlife Toxicology", which posed the hypothesis that "Human health is believed to be threatened by exposure to such chemical contaminants as agricultural pesticides and industrial waste. Does it not stand to reason, therefore, that the health of wildlife could be affected similarly by toxic chemical pollutants?".

During the early phases in the development of the field of wildlife toxicology, such as through the first annual meeting of the Society of Environmental Toxicology and Chemistry in 1980, there were only just a few papers in wildlife toxicology presented [1]. Now, with more sophisticated tools and techniques at our disposal, the issues surrounding the response of wildlife to chemical contaminants and the inter-relationship with that response to human health are still growing as an interdisciplinary study [2]. Rattner [3] provides an excellent history of wildlife toxicology dating back to ancient times and preceding to the $21^{\text {st }}$ century. Our attempts to continue to quantify the impacts of contaminants on wildlife populations remains about as difficult a task as it was 30 years ago, although this has been a period of the most rapid scientific development of wildlife toxicology. For example, how does one determine the percentage of the wildlife species that are killed outright, made more susceptible to disease or predation, or suffered reproductive impairment after exposure to toxic chemicals? Even more confounding now, related to wildlife toxicology, are emerging contaminants and biodiversity issues. For instance, the issue of global climate change not only threatens habitats of wildlife, but it can also put additional stress on wildlife species that may be exposed to environmental contaminants [2].

In this article, I will discuss how rapid expansion of environmental toxicology has produced a continuing growth of the number of wildlife toxicologists to find answers to these questions. These toxicologists continue to develop and use ecological and related acute and chronic toxicological information to study wildlife potentially affected by environmental contaminants. Wildlife toxicology has been reviewed and defined as the study of the effects of environmental contaminants on wildlife species as related to an animal's well-being, general health, and reproduction [1]. Recently, wildlife toxicology has been expanded on by Hoffman et al. [4] who noted three principle strategies for understanding xenobiotic effects of wildlife: chemical analysis, field ecology, and various controlled field studies [4]. Rattner [3] suggests that wildlife toxicology is a component of ecotoxicology and, for the most part, represents a focus on aquatic and terrestrial amphibians, reptiles, birds, and mammals. To further expand on this observation, I propose that wildlife toxicology requires an interdisciplinary approach of three major emphasis areas, which include environmental chemistry and analytical toxicology to identify the toxic substance of concern. Then, biochemical toxicology encompassing the physiological and biochemical disturbances of contaminants and their toxicokinetics provides us information as to the "mechanism of action". What has become evident in this era of scientific development in the field of wildlife toxicology is that wildlife species are not only responding to environmental contaminants, but also to disease and parasites and their interactions [5]. Finally, we must understand ecotoxicology, or the field of effects, of chemicals on both the aquatic and terrestrial environment as concerns impacts on wildlife and their populations [6] (Figure 1).

Although there are no clear taxonomic guidelines, the term "wildlife" generally pertains to vertebrate animals living in a natural, undomesticated state. In the early years, wildlife toxicology research focused on wildlife with economic benefits in terms of hunting and fishing, sources of food, nature photography, or aesthetic appreciation. This emphasis derived from the rationale that the most studied species should be either beneficial or detrimental to human society. Although "value-added" species, such as birds and mammals, are still quite important, the present discussion includes issues related to amphibians and reptiles, as these taxa have been receiving substantially increased attention in terms of their susceptibility to contaminant exposure [2] (Figure 2).

*Corresponding author: Ronald J. Kendall, Wildlife Toxicology Laboratory, Texas Tech University, Reese Center, Box 43290, Lubbock, Texas, USA, Tel: 8068850238 ; E-mail: ron.kendall@ttu.edu

Received December 23, 2015; Accepted January 18, 2016; Published January 22, 2016

Citation: Kendall RJ (2016) Wildlife Toxicology: Where We Have Been and Where We Are Going. J Environ Anal Toxicol 6: 348. doi:10.4172/2161-0525.1000348

Copyright: @ 2016 Kendall RJ. This is an open-access article distributed under the terms of the Creative Commons Attribution License, which permits unrestricted use, distribution, and reproduction in any medium, provided the original author and source are credited. 


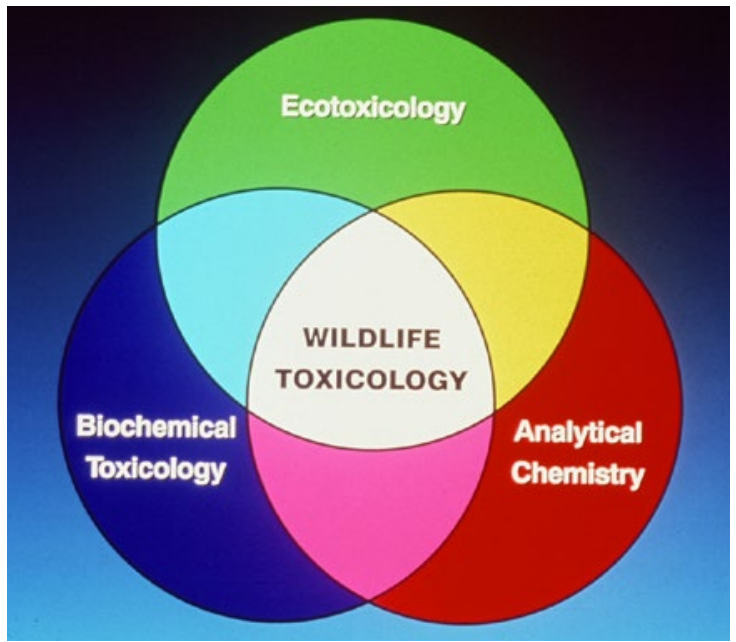

Figure 1: Wildlife toxicology requires an interdisciplinary team approach involving environmental chemistry, biochemical toxicology, and ecotoxicology, including field wildlife studies.

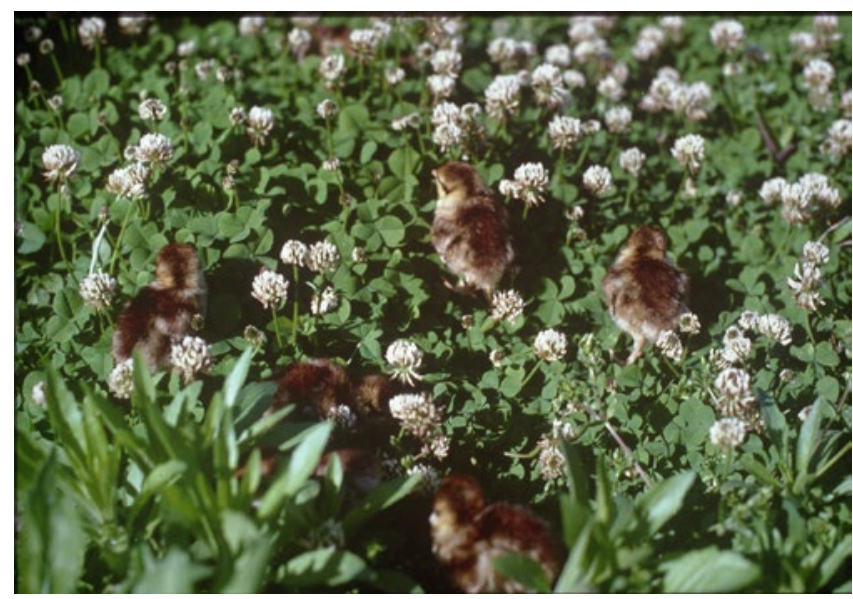

Figure 2: Oftentimes, the juvenile states of wildlife, such as in the Northern bobwhite (Colinus virginianus) brood, can be more sensitive to chemical exposure and that is why wildlife toxicology field studies still are essential in assessing the response of wildlife in the environment.

As we consider wildlife toxicology and the well-being of wildlife species, we can consider behavioral effects, such as whether there is a significant increase in the probability of being preyed upon or an aberration of migratory behavior (Figure 3).

Good general health implies that the organism or population exists in a sustainable, homeostatic condition with its environment and, therefore, can respond to various environmental situations, such as global climate change. Because the reproductive process is often very sensitive to chemical influences, these studies are high priority in wildlife toxicology. Some researchers question what is so special about wildlife toxicology that it should be identified as a particular branch of toxicology. All toxicologists have in common a primary objective: to study the mechanism and processes by which toxic substances produce adverse effects in biological systems. Such studies are based largely on the use of certain laboratory animals, animal-derived tissues or cell models regardless of whether they are conducted to assess hazards to humans or other species [4]. It is in risk assessment that a certain diversification among toxicologists becomes noticeable. Those whose primary concern is assessing chemical hazards to humans should be able to judge whether animal data are relevant to humans. They must understand the toxic substance, the comparative physiology of the test species to humans, and the potential for human exposure to the chemicals in question. Likewise, wildlife toxicologists must understand the toxic substance, biological systems, its response and the potential for exposure [7]; however, in this case, it is related to populations in the wild where there is far less experimental control and much more uncertainty (Figure 4).

\section{Wildlife Toxicology- The Early Phases}

The discovery that organochlorine pesticides reduce eggshell thickness in raptorial species is perhaps the most well-known and extensively documented event in wildlife toxicology. During the 1940s and 1950s, the British Nature Conservancy noted a decline in peregrine falcons (Falco peregrinus) across Europe. Soon thereafter, correlations between eggshell thickness and reproductive failure in these falcons, other raptors, and piscivorous avian species were discovered [8]. These findings and evidence of exposure among humans ultimately led to the ban of DDT (1,1,1-trichloro-2,2-bis( $p$-chlorophenyl)ethane) in the United States in 1973 (Figure 5).

In addition, a number of events raised society's awareness and prompted the public's interest in environmental issues and, thus, wildlife toxicology. Without question, Rachel Carson's book "Silent Spring" [9] fueled the debate on environmental contaminant effects on humans and wildlife, and brought these issues to the widespread attention of the American public. Many credit "Silent Spring" with spurring the ensuing environmental movement. Carson's cautionary words on the potential impacts of anthropogenic substances in the environment have inspired many environmental scientists to bring public awareness to this issue even to this day. In 1979, the Society of Environmental Toxicology and Chemistry (SETAC) was founded to fill the need for a professional organization dedicated to the research issues of environmental contamination. Among its early membership, SETAC included many of the wildlife toxicologists and today it remains an important organization for the dissemination of wildlife toxicology research [10]. SETAC remains the largest and most influential organization for environmental and wildlife toxicology professionals and has become global in stature and reach.

In the early days of wildlife toxicology, we saw extensive use of the relatively simple experimental methods, including the generation of $\mathrm{LD}_{50}$ and $\mathrm{LC}_{50}$ values. Generally speaking, overt lethality was the most common endpoint assessed by wildlife toxicologists. These methods were adapted from traditional toxicology. A new era of intensive synthetic chemical usage in the mid-1900s unfortunately resulted in many instances in which acute toxicity levels of contaminants created "die-offs" among wildlife. Environmental regulations evolved, slowly at times, to address the booming industrial capacity including those of the agricultural chemical industries to produce and disseminate toxic substances to the environment (Figure 6).

Discovery of wildlife mortalities in the field led wildlife toxicologists to initiate laboratory dosing experiments using wild, inbred, or domestic animal models to establish benchmark data on acute and chronic toxicity of environmental contaminants, including pesticides, petroleum, and industrial waste products. For example, Aulerich and Ringer used PCB-laden fish to evaluate lethality and reproductive impairment of mink (Mustela vison), which had begun to decline around the Great Lakes in the late 1960s and early 1970s [11]. However, to generate statistically meaningful data sets in light of 
Citation: Kendall RJ (2016) Wildlife Toxicology: Where We Have Been and Where We Are Going. J Environ Anal Toxicol 6: 348. doi:10.4172/21610525.1000348

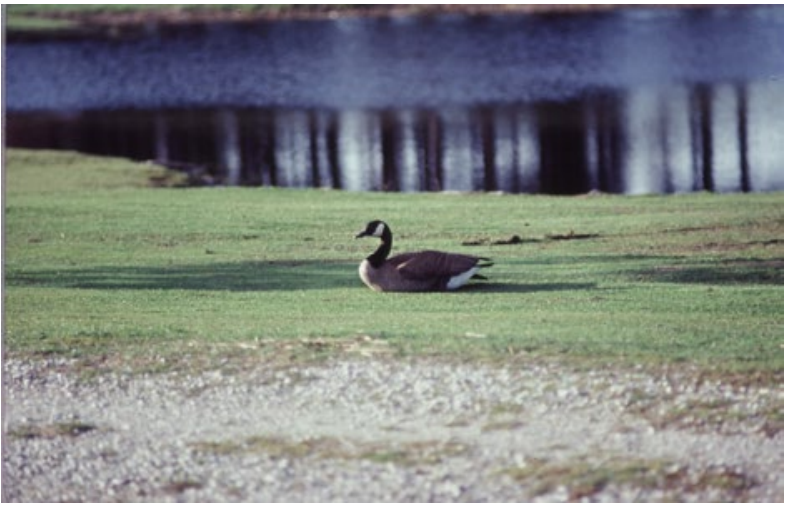

Figure 3: This Canadian goose (Branta canadensis) was observed feeding on the turf of a golf course treated with an agricultural chemical and demonstrated a behavioral toxicology response by remaining on the turf while even being approached by wildlife toxicology research personnel.

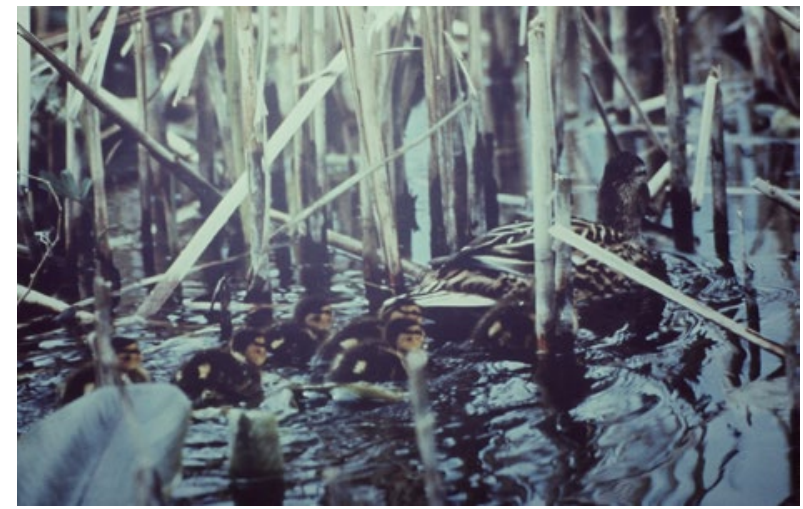

Figure 4: Wildlife, such as this mallard hen duck and her brood occupying aquatic environments close to agricultural zones, can often be very difficult to assess for agricultural chemical impacts which often dictates the need for radio telemetry.

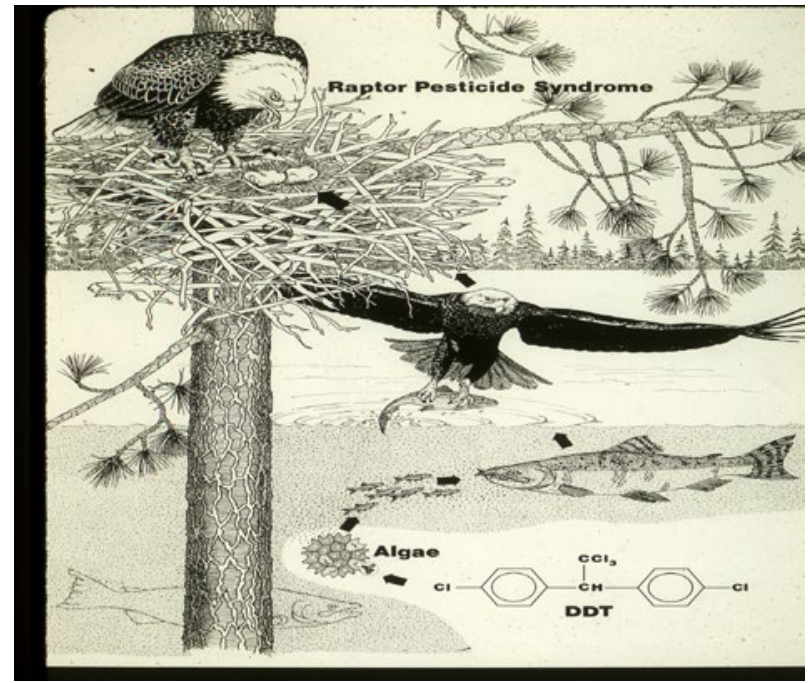

Figure 5: The bioconcentration of DDT in the food chain can result in accumulation in sensitive species such as the American bald eagle (Haliaeetus leucocephalus) that can result in eggshell thinning or "raptor pesticide syndrome" causing reproductive impairment.

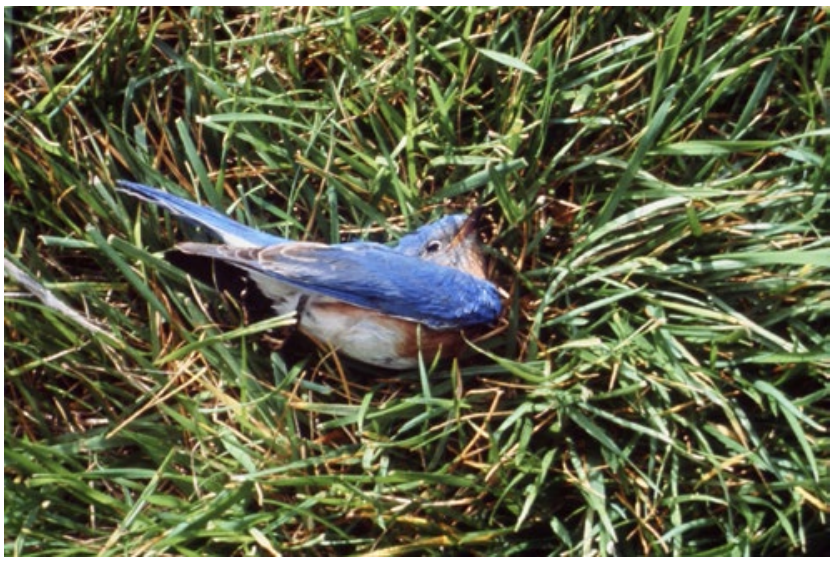

Figure 6: Dead wildlife, particularly birds, are often extremely difficult to find in the environment; thus, many wildlife mortality incidents go undetected.

inherent variability of wildlife species, many of the early wildlife toxicity studies ironically resulted in the overkill in both laboratory animals and wildlife. Efforts to develop and validate sublethal indicators of exposure and effects for sometimes critical wildlife populations were intensified. Many of the well-known environmental contaminants, such as DDT, PCBs, and various toxic heavy metals, have been studied extensively for toxicity among wildlife. Although there is still much to be learned about the effects of these chemicals alone, and especially in mixtures [12], much progress has been made over the past 30 years, the timeframe of the most rapid development of the field of wildlife toxicology [2] (Figure 7).

Today, sublethal chronic testing of single and multiple contaminants focusing on alterations in wildlife physiological processes, reproductive success, and fitness have become more common than lethality tests, which had provided the earlier benchmark toxicity values. With the increased capabilities in genetic toxicology [12], we are also able to better understand the influence of environmental contaminants on wildlife genetics, which may ultimately manifest itself toxicologically with impairment of reproduction, health, and well-being. Although it is sometimes possible in wildlife toxicology to use the actual species of interest in laboratory studies, generally data from one species must be extrapolated to another using comparative physiology. When risk assessments are conducted, wildlife toxicologists must consider hazards not only to one particular species, but to a variety of species and their ecosystems. This requires sufficient understanding of the environmental chemistry of the toxic chemicals being assessed, as well as the knowledge of the life cycles of wildlife, which may influence exposure. In this area of risk assessment, wildlife toxicologists have one major advantage over human toxicologists: opportunities sometime arise to conduct field studies to echo the impact of the chemicals in certain species or groups of species [13]. In most instances with humans, the effects of hazardous exposures to chemicals can be evaluated only indirectly. The design of field experiments in wildlife toxicology requires the combination of disciplines previously mentioned: environmental chemistry and analytical toxicology, biochemical toxicology, biostatistics, and wildlife biology and field ecotoxicology. Consequently, wildlife toxicology should be seen as a rather broad area in which scientists with different educational backgrounds and training can and should collaborate (Figure 8). 


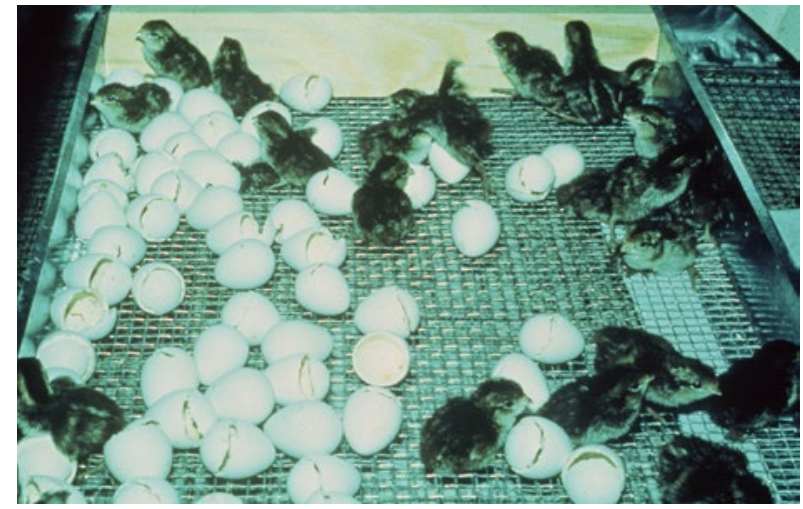

Figure 7: Northern bobwhite (Colinus virginianus) quail chicks can be hatched in the laboratory for conduct of toxicity assessment with chemicals. Although wildlife toxicologists can acquire valuable dose response information on agricultural chemicals and other toxic compounds, this still does not simulate wildlife exposure to toxic chemicals.

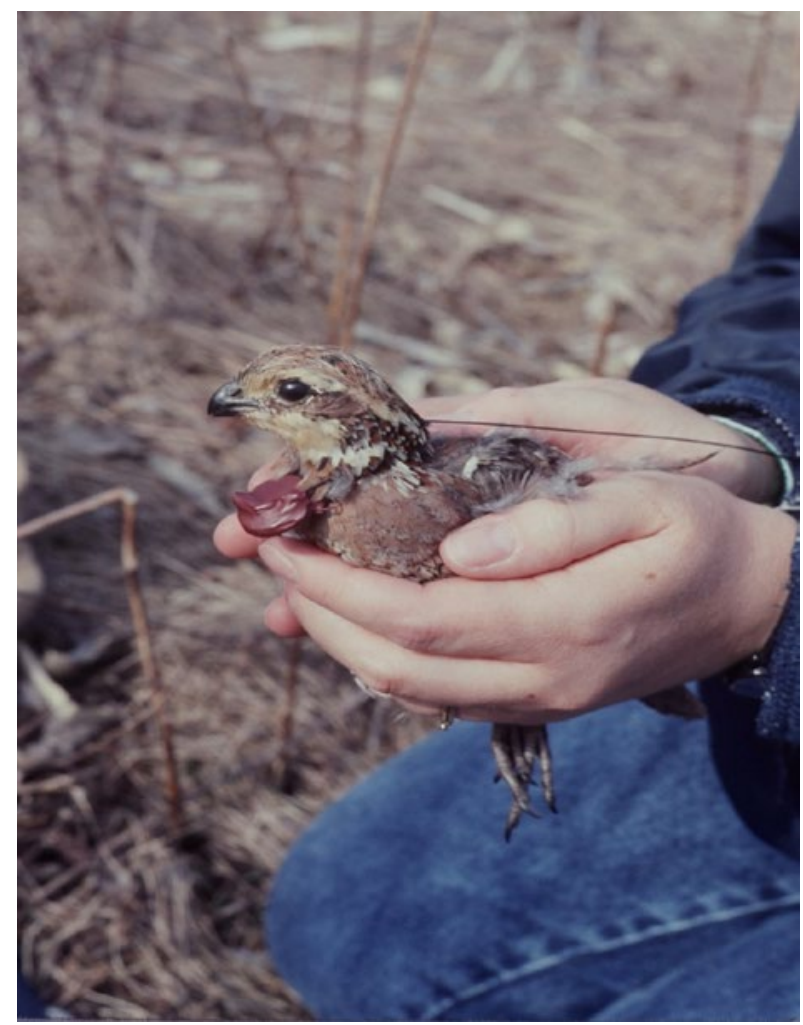

Figure 8: Northern bobwhite (Colinus virginianus) can be fitted with small radio transmitter devices and subsequently released back into the environment to determine their behavior and response to chemical exposures.

\section{Wildlife Toxicology- Strategies for Assessment}

Laboratory tests generally required for the development of risk assessment in wildlife are limited, providing only basic toxicological and biochemical characteristics of the test product in free-ranging wildlife. If preliminary wildlife testing, when available, indicates that a substance may harm wildlife, then field testing may be required for an ecological risk assessment. Prior to the initiation of such testing, a chemical, such as a pesticide, is evaluated to characterize potential impacts such as mortality, behavior effects, and biochemical and/or physiological disturbances.
Initial testing generates acute toxicity data through $\mathrm{LD}_{50}$ and/or $\mathrm{LC}_{50}$ determinations, in addition to laboratory reproductive toxicity data. Also, representative species present in a geographic area of planned field tests can be exposed to the compound under laboratory conditions to obtain lethality and toxicity data. These studies maximize the use of the test animals, not simply by quantifying mortality but also by evaluating behavioral and biochemical impacts of the chemical or toxic substance. In the case of organophosphate (OP) pesticides for example, which have been relatively well-studied in relation to wildlife toxicology, cholinesterase activities are measured in both blood and brain tissues.

The use of plasma cholinesterase activities in live-trapped wild animals has several benefits compared to conventional brain cholinesterase analysis. First, it allows multiple captures and samplings from radio-tagged or otherwise marked animals so that biochemical toxicity in individuals can be evaluated over time [14]. Depression of plasma cholinesterase, occurring with exposures well below lethal levels, best provides a very sensitive, nonlethal means of establishing low level OP exposure in wildlife, particularly birds that have been well-studied.

Sublethal effects of pesticides on behavior of wildlife have also been examined. For instance, Northern bobwhite (Colinus virginianus) have been assessed for predator evasion responses subsequent to being exposed to the organophosphate pesticide, methyl parathion (phosphorothioic acid, O,O-dimethyl O-(4-nitrophenyl) ester). The organophosphate-treated birds were less capable of escaping predators than were controls in simulated environments [15]. The activity and mortality of radio-tagged Northern bobwhites exposed to nonlethal doses of methyl parathion and released back into their natural habitat have also been evaluated [16]. Multi-year tests have shown that methyl parathion-exposure bobwhites are more susceptible to predation, primarily from raptors. The evidence also suggests that exposure to OPs may influence the integrity of Northern bobwhite coveys. Individuals suffering from acute toxicity may have difficulty maintaining covey affiliation, a behavior important for survival and predator detection in this species. These examples provide insight as to how disturbed behavior can ultimately manifest itself in the impairment or death of exposed wildlife.

\section{Reproductive Assessments}

In terms of reproductive toxicity, which is often difficult to measure with environmental contaminants, studies with European starlings (Sturnus vulgaris) have used enhanced local populations attracted into test fields with artificial nest boxes. These tests have led to greater insight into the reproductive success of passerine species exposed, for instance, to organophosphate pesticides [17] (Figure 9).

The starling is an excellent species for use in environmental monitoring. It is geographically widespread and utilizes many habitat types. As an introduced species in North America, it has acquired the status of pest species, thus increasing its acceptability as a wild test organism. Nest boxes placed in study fields are readily utilized, providing a large synchronistic breeding population of passerines on the treatment site. The starlings' diet during the breeding season consists predominantly of terrestrial invertebrates that live in direct contact with pesticides present in the soil. An additional benefit is the starlings' tolerance of handling monitoring methods used to quantify breeding success. This provides an example of the necessary strategy for identifying the wildlife to sample and assess for contaminant impacts (Figure 10). 


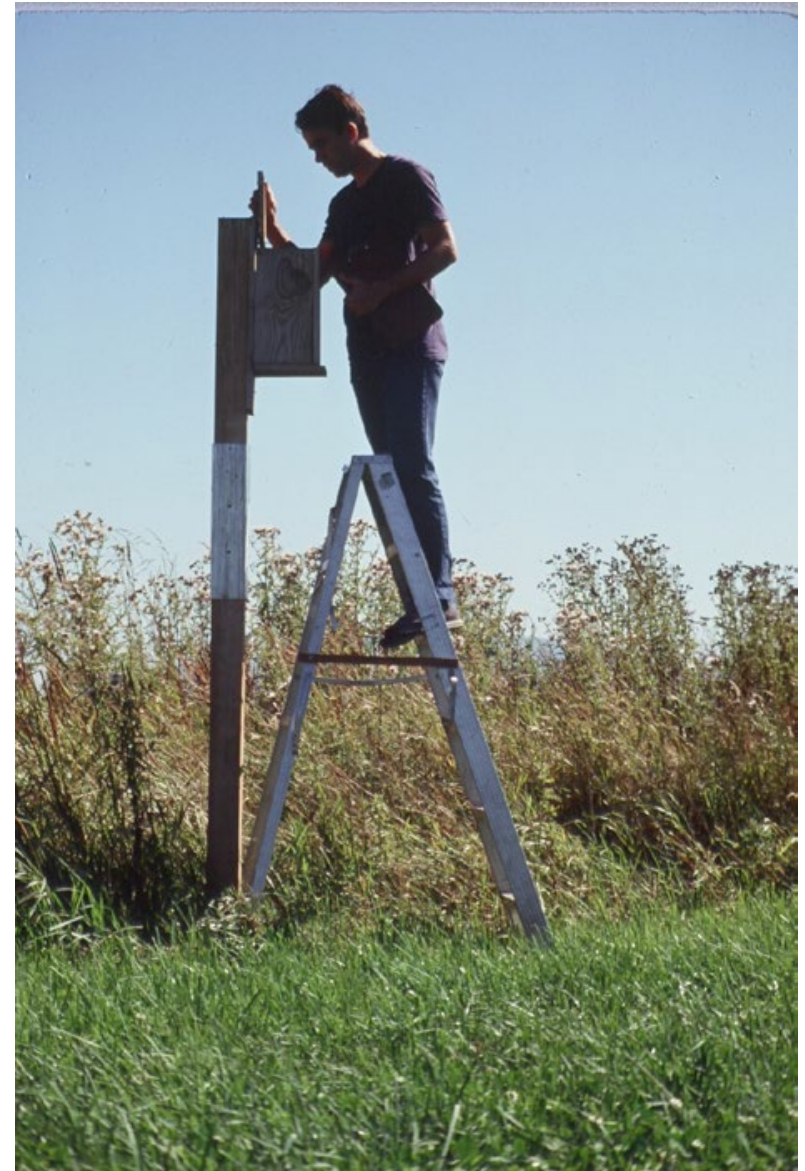

Figure 9: European Starling (Sturnus vulgaris) nest boxes deployed into agricultural zones allow valuable samples to be collected from foraging adults that may be laying eggs in the boxes and/or feeding young.

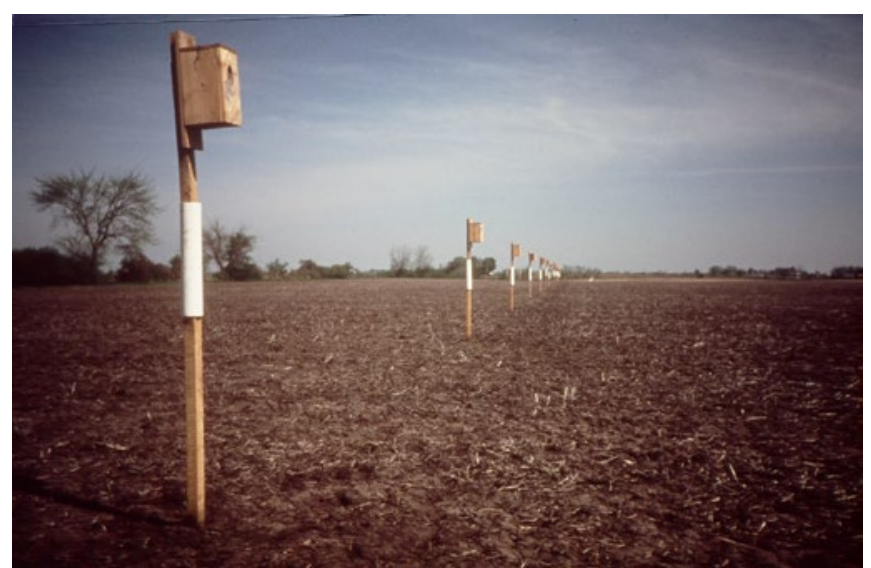

Figure 10: Avian nest boxes can be deployed through the center of agricultura fields with pre-emergent crops to look at the process of agricultural chemical utilization and its potential impacts on birds.

The enhanced avian population model entails the establishment of starling nest boxes on study sites. One or more of the sites are treated with the chemical of interest, such as a pesticide. In field tests with the organophosphate methyl parathion, control birds had $48 \%$ successful nesting (fledging at least one bird from the nest) while those in the field treated with one kilogram of methyl parathion per hectare had only a
$19 \%$ success rate [18] (Figures 11-14).

Nestboxes placed in agroecosystems not recently treated with pesticides had provided healthy nestlings that had been evaluated in the nest with their responses to increasing levels of the organophosphate pesticide diazinon(phosphorothioic acid O,O diethyl-O-[6methyl-2(1-methyl ethyl-4-pyrimidinyl]ester). The compound was administered orally in a corn oil vehicle to evaluate the differential sensitivity between nestling starlings of different ages. Newly hatched young were nearly 20 times more sensitive to an acute dose of diazinon when compared with fledglings [19].

As previously mentioned, in the 1980s wildlife toxicology showed a substantial increase in the number of field studies being conducted to rebut the presumption of risk, particularly of pesticides exposure to wildlife through the EPA Pesticide Registration Process. Field studies conducted in the early to mid-1980s on the effects of pesticides in birds generally included environmental chemistry data and response of birds (including mortality) to applied pesticides [20]. The EPA subsequently evolved a set of criteria upon which pesticide field studies could be conducted at various levels of effort [21].

These levels of effort for field studies included Level 1 and Level 2 field studies as designated by EPA (Figure 15).

A level one field study generally involves mortality as a key endpoint for a variety of sites treated with pesticides and assessed for the response of birds and other wildlife possibly exposed to the chemical. Some residue analyses as well as behavioral observations were employed. These level one studies were generally known as "screening trials" and were more a qualitative assessment of the potential hazard of the pesticide or other toxic chemical to birds and other wildlife that may utilize habitats receiving such agents, for instance. Data acquired from level one field trials then made it possible for an assessment of higher levels of study, or a level two study. A level two field study sought to quantify a response of wildlife populations to chemicals such as agricultural pesticides. This quantification can take the form of the extensive chemical analyses, radio telemetric monitoring techniques, and starling nest box studies. Conducting a field experiment generally includes a number of sites for sufficient replication in a variety of observations that allow quantification of the response of wildlife to chemicals in terms of the reproduction, health, and well-being [14]. A level two field study conducted in Iowa to assess the response of wildlife to the corn root worm insecticide Counter 15-G (terbufos; phosporodithioic acid S-[(1,1-dimethylethyl)thio]\{O, O diethyl) was submitted to the EPA to meet requirements of FIFRA guidelines [22]. This is one of only a few known studies that have ever been submitted to the EPA to address level two requirements. Data generated from level one and, particularly, level two field studies provide useful information for the development of ecological models related to the effects of the pesticides in avian and other wildlife species. Although very few pesticide-related field studies are conducted currently in the field of wildlife toxicology, their need is still extremely important when trying to fully understand the response of wildlife in their natural habitats to toxic chemical exposure (Figures 16 and 17).

The issue of toxic heavy metal exposure in wildlife has continued to challenge wildlife toxicologists and a prime example, lead, has exerted effects on wildlife, and particularly birds. Spent lead shot has been identified as a major environmental concern in waterfowl health as a result of numerous studies that began in the early 1900s and intensified in the late 1950s. For instance, these studies identified the ingestion of spent lead shot as a major hazard in North American waterfowl [23]. 
Citation: Kendall RJ (2016) Wildlife Toxicology: Where We Have Been and Where We Are Going. J Environ Anal Toxicol 6: 348. doi:10.4172/21610525.1000348

\begin{tabular}{lcc}
\multicolumn{3}{l}{ SUCCESSFUL NESTS FOR ENTIRE STUDY * } \\
\hline FIELD & \# SUCCESSFUL / \# COMPLETE & PERCENT \\
\hline Control 1 & $23 / 45$ & 51 \\
Control 2 & $28 / 53$ & 53 \\
Treatment 1 & $07 / 40$ & 18 \\
Treatment 2 & $09 / 42$ & 21 \\
& & \\
\hline \multirow{3}{*}{ * } & & \\
flefined as any nest in which at least 1 nestli \\
\end{tabular}

Figure 11: European Starling (Sturnus vulgaris) nesting success in agricultural fields treated with methyl parathion, an organophosphate pesticide, were substantially lower than in control fields.

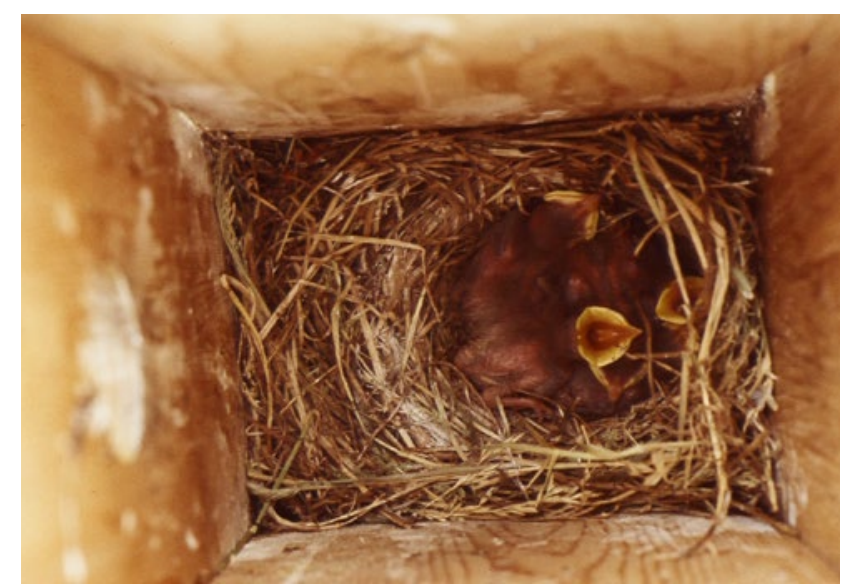

Figure 12: European Starlings (Sturnus vulgaris) nestlings hatching in deployed nesting boxes can be easily accessed for blood sampling of the young and, particularly, for evaluating contaminated diet that may be brought to the nestlings by adults from contaminated sites.

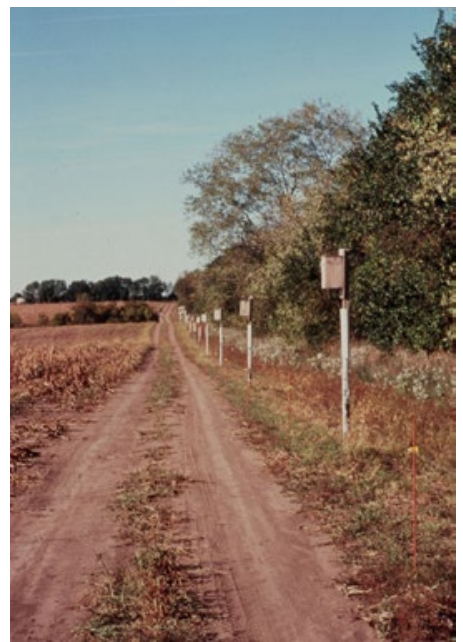

Figure 13: Avian nesting boxes can be deployed on the perimeter of agricultural fields, such as this corn field in lowa, to determine response to the use of agricultural chemicals.

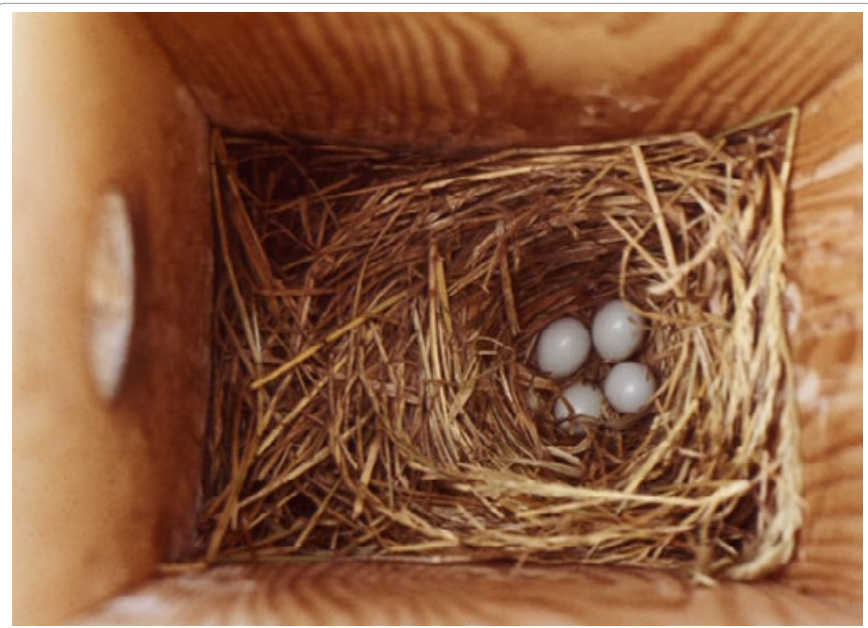

Figure 14: Wildlife toxicologists use nesting boxes near toxic sites to assess birds exposure and/or impacts form chemicals.

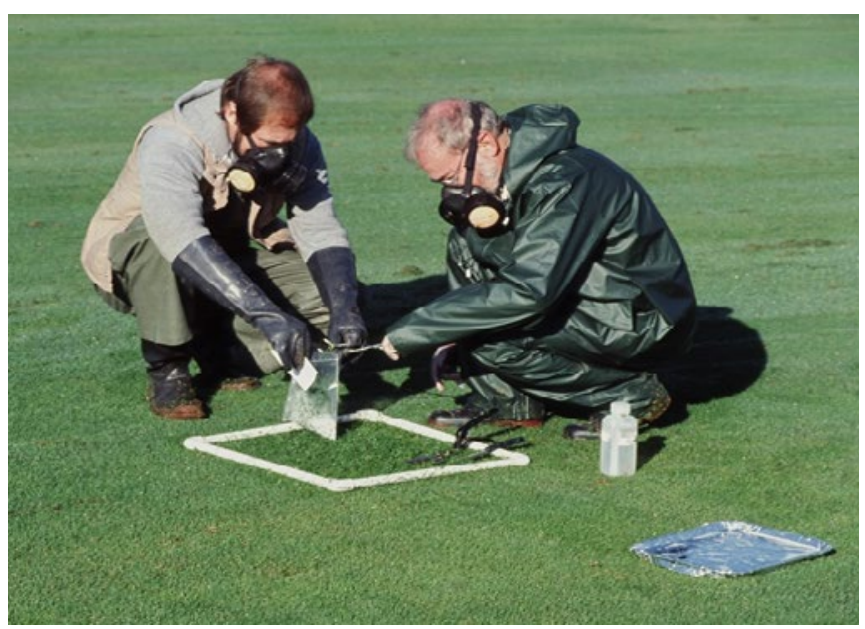

Figure 15: Wildlife field studies also involve environmental chemistry assessment of chemicals, such as in this case of golf course turf application of agricultural chemicals, which may contaminate grass eaten by various wildlife species.

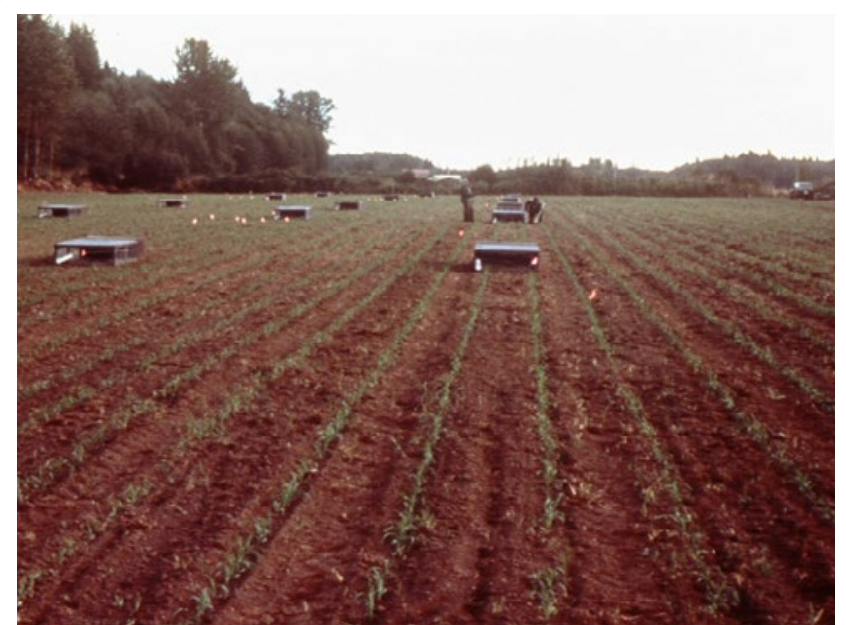

Figure 16: In wildlife toxicology field studies, small pen field enclosures oftentimes prove valuable, particularly to determine potential exposure to agricultural chemicals utilized in agriculture. 


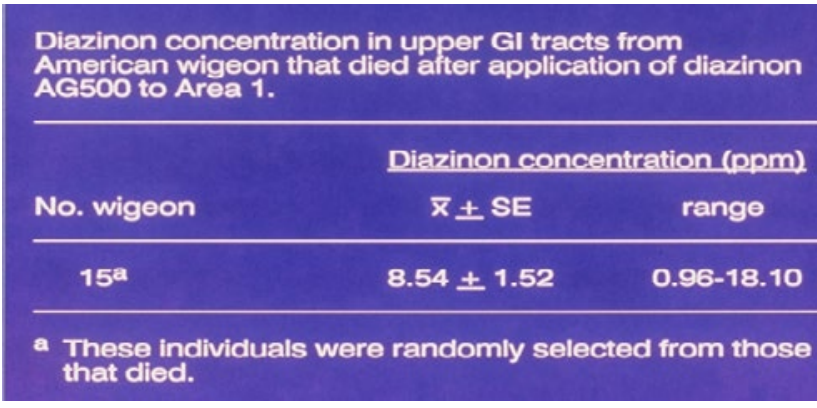

Figure 17: In studies with diazinon AG500, a widely used turf organophosphate insecticide, American wigeon (Anas americana) were revealed to be extremely sensitive to this product in studies on golf courses of the Pacific Northwest of the United States.

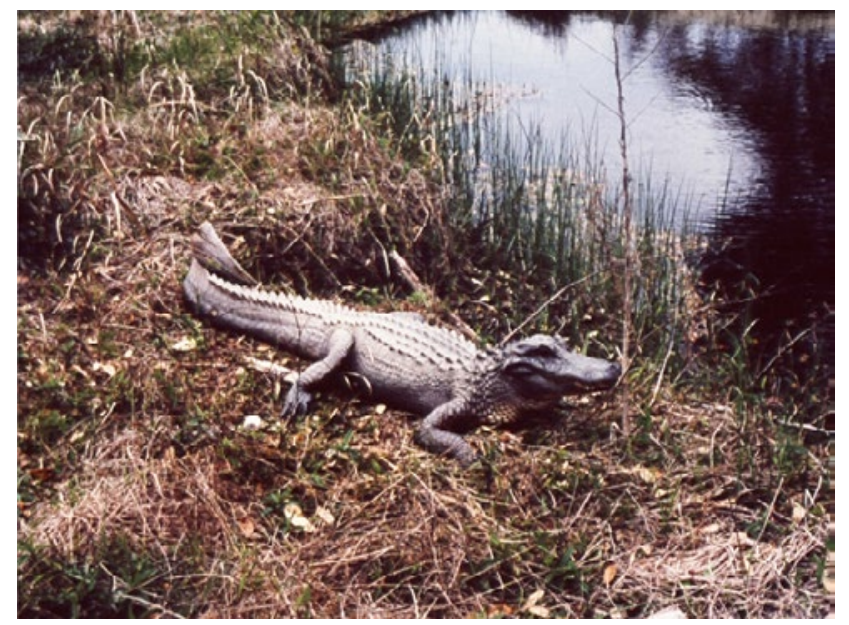

Figure 18: Early reports of alligators (Alligator mississippiensis) exposed to chemicals in Lake Apopka, Florida, fueled much of the early debate on "endocrine disrupting compounds" that were ultimately regulated under the 1996 Food Quality and Protection Act.

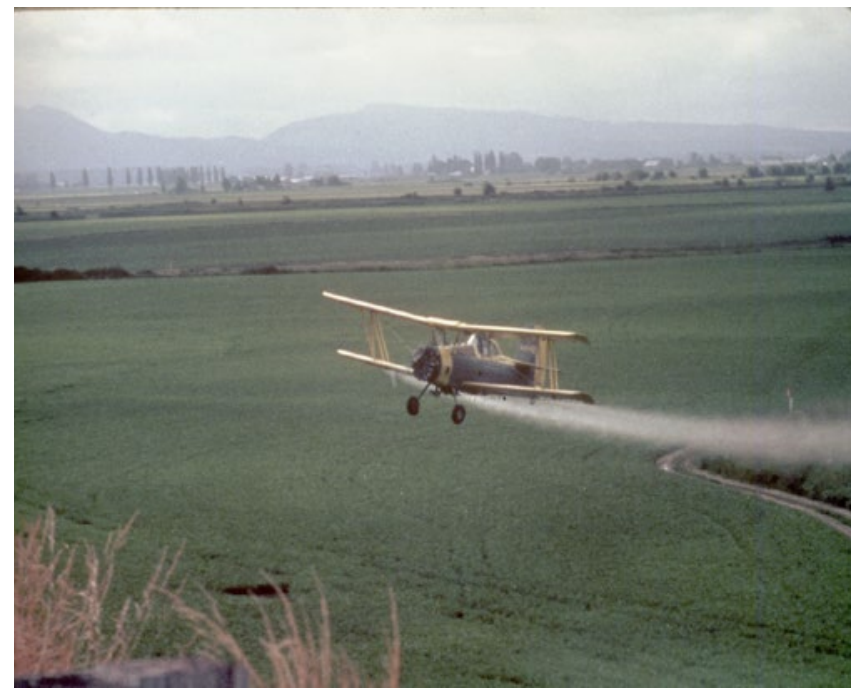

Figure 19: Although it is cost effective and increases capability of treating large areas, aerial application of agricultural chemicals creates many additional exposure scenarios for wildlife, particularly involving drift that can be challenging in wildlife toxicology field studies.
In North America, it was estimated that between 1.5 million and 2.5 million waterfowl were lost annually to lead poisoning. This drew great concern, particularly from sportsmen, in the United States related to waterfowl hunting and ultimately lead shot was regulated out of use for waterfowl hunting and substituted with steel shot regulation. Concern for waterfowl exposure to spent lead shot resulted in concern for upland game birds, particularly mourning dove (Zenaida macroura) as well as raptors. Kendall et al. [24] were commissioned to conduct an ecological risk assessment of lead shot exposure in non-waterfowl avian species, particularly upland game birds and raptors. There is evidence that bald eagles (Haliaeetus leucocephalus) and other raptors that fed on lead shot embedded in the tissues or present in the intestinal tract of waterfowl demonstrated acute and chronic symptoms of lead poisoning. The poisoning of bald eagles by lead shot was the impetus for the final decision to ban the use of lead shot for hunting waterfowl [25]. Evidence does exist that upland birds, particularly mourning doves, that are heavily hunted with lead shot may ingest spent lead shot. Mortality, neurological dysfunction, immune suppression, and reproductive impairment are documented effects of exposure to lead in birds and considering that large amount of spent lead shot are released into the environment each year from sport shooting and hunting, exposure is possible, particularly considering doves that are attracted to hunting fields and may ingest spent lead shot while feeding on grains, for instance. Although this ecological risk assessment does not clearly define significant risk of lead exposure to upland game birds, particularly doves, Kendall et al. does strongly recommend continued scrutiny to protect our upland game birds and raptor resources.

\section{Endocrine Disruption}

The 1990s presented several issues which directly impacted wildlife toxicology, but endocrine disrupting properties topped the list. With the passage of the Food Quality Protection Act of 1996, the U.S. Congress charged the U.S. EPA to address scientific questions regarding the potential for chemicals to cause endocrine disruptions in both humans and wildlife. With the hypothesis, these compounds impact reproduction of wildlife, Theo Colborn's book "Our Stolen Future" stimulated an intense debate [26]. Guillette et al. [27] have previously reported alterations in alligator (Alligator mississippiensis) sex hormones and gonadal development related to environmental contaminants in Florida. The combination of legislation and other findings generated intense scientific debate, workshops, and ultimately books addressing the potential influence of contaminants on endocrine function [28]. In response, the EPA established the Endocrine Disruptor Screening and Testing Advisory Committee (EDSTAC), on which I participated, to examine this issue and make recommendations on testing and regulation of endocrine disrupting chemicals. Endocrine disruptors remain an issue of concern as new chemicals with these types of properties are identified. Recently, perchlorate, a thyroid hormone inhibitor, gained national attention because of its widespread distribution in groundwater and surface water supplies. Perchlorate detected in numerous plants, fish, and wildlife species [29] can effectively inhibit metamorphosis and shift sex ratio in amphibians [30]. As endocrine altering chemicals continue to emerge, the demand for studies to examine the effects on wildlife will increase. In fact, even at the time of the preparation of this manuscript, industry is preparing to extensively increase testing on the effects of endocrine disrupting compounds in wildlife (Figure 18).

\section{Deep-water Horizon Gulf Oil Spill}

In the summer of 2010, the Deep-water Horizon oil spill disaster 


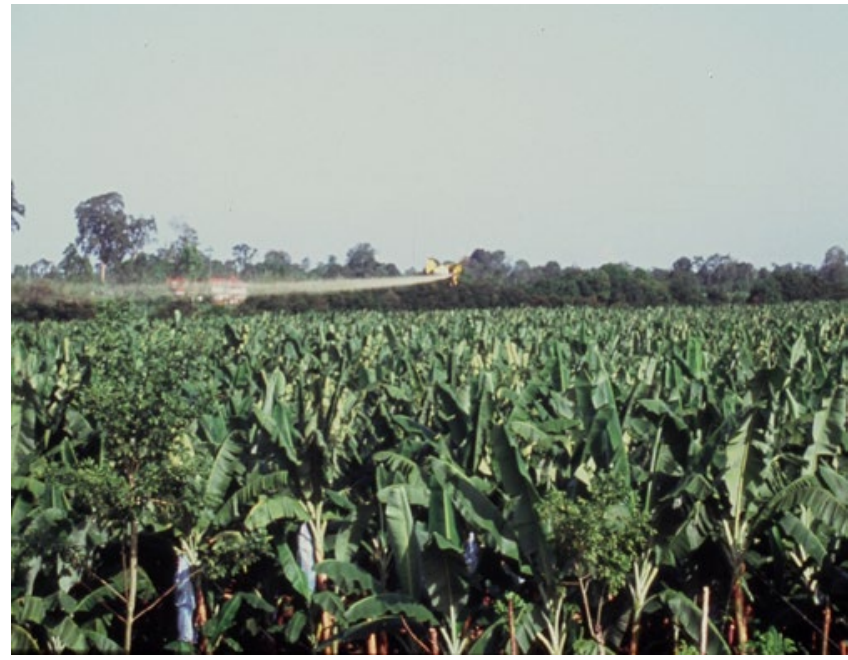

Figure 20: Agricultural chemicals utilized in the tropics, such as this fungicide spraying in a banana plantation in Costa Rica, create many complex challenges for wildlife toxicologists to study response of wildlife in these situations.

ultimately released close to 800 million liters of crude oil into the Gulf of Mexico. This oil, in addition, was treated with dispersants, particularly Corexit 9500, both on the surface as well as at the wellhead of the damaged Deep-water Horizon oil rig. The concomitant heavy use of dispersants associated with the largest oil spill in U.S. history resulted in a massive ecotoxicological experiment in the Gulf of Mexico in the summer of 2010 and continues. Perhaps most disconcerting is the uncertainty of how dispersant-oil mixtures may influence the ecology of the gulf. When considered holistically, the Gulf ecosystem spanning the deep ocean, continental shelf, bays, estuaries, and marshlands is extraordinarily interconnected and complex. Data are still unfolding as to the assessment of both fish and wildlife toxicology issues associated with this massive release of oil. Crude oil is a complex mixture of thousands of chemical compounds; however, the aromatic hydrocarbons (both simple and polycyclic) are considered the most toxicologically important. To date, thousands of birds, hundreds of endangered sea turtles, and other wildlife have either died or been impaired from the Deep-water Horizon Gulf oil spill.

Take, for instance, the Kemp's ridley sea turtle (Lepidochelys kempii), an endangered species for which extensive recovery efforts have been made, is under great threat from this massive release of oil. Many female Kemp's ridleys nest along the coast of Texas before returning to the Gulf [31]. Then, they head to the feeding grounds, often off Louisiana or the west coast of Florida. The Kemp's ridley sea turtle utilizes the Gulf of Mexico ecosystem throughout its life cycle [32]. To date, we have seen hundreds of dead turtles reported through the summer of 2010. Kemp's ridley sea turtles are highly susceptible to anthropogenic stressors, like oil spills, which may cause mortality or disrupt normal behaviors. When Kemp's ridley eggs hatch, the young, which may only be $4 \mathrm{~cm}$ long, return to the ocean where they will leave the nearshore environment and enter an open ocean developmental stage entering the Gulf currents, feeding predominantly on jellyfish, fish, and crabs [33]. It is thought that young turtles at sea may associate with Sargassum for refuge, rest, and/or feed. Oil and/or dispersant impacts on seaweed could result in serious negative impacts among young turtles. If oil affects the food supply of the Kemp's ridley and disturbs critical stages of its life cycle, we may not see oiled dead Kemp's ridleys to a great extent, but their population abundance could be in peril by subtle, indirect effects of dispersed oil on the environment and their food chain. This is just one species among many that could be dramatically impacted as we look into the future related to the Deepwater Horizon Gulf oil spill event and wildlife toxicology will play an important role in assessing impact and confirming restoration in the Gulf in the years ahead [34].

\section{The Future}

Wildlife toxicology now has more access to sophisticated technologies than were available 30 years ago when the field really began to emerge as a dynamic area of toxicology research. New analytical equipment and more economical technologies, such as enzyme-linked immunosorbent assays, passive sampling devices, and accelerated solvent extractors have improved detection capabilities and removed many of the restrictions on measuring contaminants in various environmental matrices. For example, until the 1990s, no reliable method was available to detect perchlorate in water at the parts per billion concentrations now commonly detected in environmental samples. Scientists at the California EPA developed a more sensitive method in the 1990s, which was sensitive enough to reveal widespread contamination of ground and surface waters in the state and elsewhere. The analytical method was evaluated and refined for detection of perchlorate in soil, sediments, and plants [35]. A method for tissue was developed at a later time [36]. Tools for assessing physiological changes in wildlife related to environmental contaminants have also become increasingly more sophisticated. Polymerase chain reaction, DNA fingerprinting, cDNA microarrays, and other molecular techniques now provide more detailed information on the impacts of chemicals beyond individual and cellular levels. Thus, studies of contaminant effects on wildlife today may include measurement endpoints on all levels from molecular, cellular, organ system, individual, and population to entire ecosystems (Figure 19).

Clearly, the health of the environment influences the viability of people and wildlife. Current risk assessments of chemicals in the environment that establish protective limits for humans often rely on wildlife exposure data. Therefore, wildlife toxicologists have an opportunity to participate in regulatory processes aimed at protecting environmental and human health. Indeed, efforts to standardize what wildlife toxicity values have proven to be very difficult due to the variability in toxicity values driven by differences in various studies to derive dose estimation methods as well as employing uncertainty factors [37] (Figure 20).

\section{Future Problems}

The issue of climate change will continue to challenge wildlife toxicologists in evaluating toxic chemicals compounded with climate change patterns. In addition, change in climate patterns may also exacerbate the issue of emerging diseases and/or parasitic infections in wildlife [38]. Obviously, this will be an evolving issue, but one that wildlife toxicologists will need to continue to keep an eye on in the future. We cannot ignore the continued expansion of oil exploration and production globally and the release of well contamination into sensitive wildlife habitats, which can have dramatic and devastating consequences. An emerging area continues to be the rapid development of the nanotechnology industry and the release of nanoparticles into the environment, exposing fish and wildlife resources. The area of nanotoxicology continues to grow, but it is still relatively in its infancy, and we are trying to better understand the ecological risk of the release of nanomaterials into the environment. 
New pesticide products, particularly neonicotinoid pesticides, are a new hot topic area. Obviously, as pests evolve and adapt to changing agriculture and/or climate patterns, new pesticides will need to be developed. Once thought to be a relatively "safe" pesticide, neonicotinoids now have been posed to cause risks to wildlife and are raising questions related to wildlife toxicity.

The field of wildlife toxicology continues to evolve while maintaining its original interdisciplinary nature by enlisting diverse specialists to help understand complexities of contaminant movement, fate, bioavailability, and physiological, population, and ecosystem effects $[2,39]$.

\section{References}

1. Kendall RJ (1982) Wildlife Toxicology. Environ Sci Technol 16: 448A-453A.

2. Kendall RJ, Lacher TE, Cobb GP, Cox SB (2010) Wildlife Toxicology: Emerging Contaminant and Biodiversity Issues. CRC Press/Taylor \& Francis Group. p: 231.

3. Rattner BA (2009) History of wildlife toxicology. Ecotoxicology 18: 773-783.

4. Hoffman DJ, Rattner BA, Hall RJ (1990) Wildlife Toxicology. Environmental Science and Technology 24: 276-283.

5. Artois M, Blancou J, Dupeyroux O, Gilot-Fromont E (2011) Sustainable control of zoonotic pathogens in wildlife: how to be fair to wild animals? Rev Sci Tech 30: 733-743

6. Kendall RJ, et al. (2001) Casarett \& Doull's Toxicology: The Basic Science of Poisons. 6th edn. Klassen CC, (eds.) McGraw-Hill, New York. p: 29.

7. Kendall RJ (1992) Farming with Agrochemicals: The Response of Wildlife Environmental Science and Technology 26: 239-245.

8. Ratcliffe DA (1967) Decrease in eggshell weight in certain birds of prey. Nature 215: $208-210$

9. Carson R (1962) Silent Spring. Houghton-Mifflin: Boston.

10. Kendall RJ (2008) Wildlife Toxicology: Integration of Ecological and Toxicological Research Strategies. Society of Environmental Toxicology and Chemistry 29th Annual Meeting, Tampa, FL, USA.

11. Aulerich RJ, Ringer RK (1977) Current status of PCB toxicity to mink, and effect on their reproduction. Arch Environ Contam Toxicol 6: 279-292.

12. Matson CW, Gillespie AM, McCarthy C, McDonald TJ, Bickham JW, et al. (2009) Wildlife toxicology: biomarkers of genotoxic exposures at a hazardous waste site. Ecotoxicology 18: 886-898.

13. Balk F, Koeman JH (1984) Future Hazards for Pesticide Use. Environmentalist 4: 1-100.

14. Kendall RJ, Lacher Jr TE (1994) Wildlife Toxicology and Population Modeling: Integrated Studies of Agroecosystems. Lewis Publishers/CRC Press. p: 576.

15. Galindo JC, Kendall RJ, Driver CJ, Lacher TE Jr (1985) The effect of methy parathion on susceptibility of bobwhite quail (Colinus virginianus) to domestic cat predation. Behav Neural Biol 43: 21-36.

16. Buerger TT, Kendall RJ, Mueller B, DeVos T, Williams BA (1991) Effects of Methyl Parathion on Northern Bobwhite Survivability. Environmental Toxicology and Chemistry 19: 527-532.

17. Kendall RJ, Brewer LW, Lacher TE, Marden BT, Whitten ML (1989) The Use of Starling Nest Boxes for Field Reproductive Studies: Provisional Guidance Document and Technical Support Document. USEPA, USA.

18. Robinson SC, Kendall RJ, Driver CJ, Lacher Jr TE, Robinson R (1988) Effects of Agricultural Spraying of Methyl Parathion on Cholinesterase Activity and Reproductive Success in Wild Starlings (Sturnus vulgaris). Environmental Toxicology and Chemistry 7: 343-349.

19. Hooper MJ, Brewer LW, Cobb GP, Kendall RJ (1990) An Integrated Laboratory and Field Approach for Assessing Hazards of Pesticide Exposure to Wildlife. In Pesticide Effects of Terrestrial Wildlife. Somerville L, Walker CH (Eds.). Taylor \& Francis, New York, USA.

20. Brewer LW, Driver CJ, Kendall RJ, Galindo JC, Dickson GW (1998) Avian Response to a Turf Application of Triumph® 4E. Environmental Toxicology and
Chemistry 7: 391-401.

21. Fite EC, Tuner LW, Cook NJ, Stunkard C (1988) Guidance Document for Conducting Terrestrial Field Studies. USEPA, Washington DC, USA.

22. Kendall RJ, Ackerman J (1992) Terrestrial Wildlife Exposed to Agrochemicals: An Ecological Risk Assessment Perspective. Environmental Toxicology and Chemistry 11: 1727-1749.

23. Bellrose FC (1959) Lead Poisoning as Mortality Factor in Waterfowl Populations Illinois Natural History Survey Bulletin 27: 235-288.

24. Kendall RJ, Lacher Jr TE, Bunck C, Daniel FB, Driver C, et al. (1996) An Ecological Risk Assessment of Lead Shot Exposure in Upland Game Birds and Raptors. Environmental Toxicology and Chemistry 15: 4-20.

25. US Fish and Wildlife Service (1986) The Use of Lead for Hunting Migratory Birds in the United States. Final Supplemental Environmental Impact Statement on the use of Lead Shot for Hunting Migratory Birds. FES 86-16. Office of Migratory Bird Management, Washington DC, USA.

26. Colborn T, Dumanoski D, Myers JP (1996) Our Stolen Future. Plume: New York.

27. Guillette Jr LJ, Gross TS, Masson GR, Matter JM, Percival HE, et al (1994) Developmental Abnormalities of the Gonad and Abnormal Sex Hormone Concentrations in Juvenile Alligators from Contaminated and Control Lakes in Florida. Environmental Health Perspectives 102: 680-688.

28. Kendall RJ, Dickerson RL, Giesy JP, Suk WA (1998) Principles and Processes for Evaluating Endocrine Disruption in Wildlife. Society of Environmental Toxicology and Chemistry (SETAC) Press, Pensacola, FL, USA. p: 491

29. Smith PN, Theodorakis CW, Anderson TA, Kendall RJ (2001) Preliminary assessment of perchlorate in ecological receptors at the Longhorn Army Ammunition Plant (LHAAP), Karnack, Texas. Ecotoxicology 10: 305-313.

30. Goleman WL, Urquidi LJ, Anderson TA, Kendall RJ, Smith EE, et al. (2002) Environmentally Relevant Concentrations of Ammonium Perchlorate Inhibit Development and Metamorphosis in Xenopus laevis. Environ Toxicol Chem 21: $424-430$

31. Seney EE, Landry Jr AM (2008) Movements of Kemp's Ridley Turtles Nesting on the Upper Texas Coast: Implications for Management. Endangered Species Research 4: 73-84.

32. Shaver DJ, Schroeder BA, Byles RA, Burchfield PM, Pena J, et al. (2005) Movements and Home Ranges of Adult Male Kemp's Ridley Sea Turtles (Lepidochelys kimpii) in the Gulf of Mexico Investigated by Satellite Telemetry. Chelonian Conservation and Biology 4: 817-827.

33. Schmid JR, Witzell WN (1997) Age and Growth of Wild Kemp's Ridley Turtles (Lepidochelys kempii): Cumulative Results of Tagging Studies in Florida. Chelonian Conservation and Biology 2: 532-537.

34. Kendall RJ (2010) Testimony to the US Senate Committee on Environmenta and Public Works. Oversight Hearing on the Use of Oil Dispersants in the Deepwater Horizon Oil Spill.

35. Ellington JJ, Evans JJ (2000) Determination of perchlorate at parts-per-billion levels in plants by ion chromatography. J Chromatogr A 898: 193-199.

36. Anderson TA, Wu TH (2002) Extraction, cleanup, and analysis of the perchlorate anion in tissue samples. Bull Environ Contam Toxicol 68: 684-691.

37. Mayfield DB, Fairbrother A (2012) Efforts to Standardize Wildlife Toxicity Values Remain Unrealized. Integr Environ Assess Manag 9: 114-123.

38. Heuvelink AE, Zwartkruis JT, van Heerwaarden C, Arends B, Stortelder V, et al. (2008) Pathogenic bacteria and parasites in wildlife and surface water. Tijdschr Diergeneeskd 133: 330-335.

39. Beasley V (2009) One toxicology, ecosystem health and one health. Vet Ita 45: $97-110$. 